\title{
Design Strategy of Emergency Pools at Source Water Protection Areas
}

\author{
Yan Lu* \\ Shanghai Lande Highway Construction \& Consulting Design Co., Ltd., Shanghai 200072, China \\ *Corresponding author: Yan Lu, luyan_jenny@hotmail.com
}

Copyright: ( $) 2022$ Author(s). This is an open-access article distributed under the terms of the Creative Commons Attribution License (CC BY 4.0), permitting distribution and reproduction in any medium, provided the original work is cited.

\begin{abstract}
The pollution problem arising from the flushing of initial rainwater and wastewater from accidents while transporting dangerous goods to source water protection areas needs to be solved as soon as possible. Therefore, the design of corresponding environmental protection measures should be considered in the engineering design stage. It is necessary to analyze the specific work in combination with engineering examples. Under this background, this paper first briefly expounds the precautions in accident risk analysis and the design of tank capacity and tank body. Finally, by analyzing actual cases, this paper systematically studies the design strategy of emergency pool in source water protection area, hoping to provide new development ideas for the upgrading of relevant work.
\end{abstract}

Keywords: Source water protection; Emergency pool; Engineering design

Online publication: January 12, 2022

\section{Introduction}

With the rapid development of urban construction, the ecological environment is bound to be affected, and the problems would be more prominent for the road drainage project passing through the source water protection area. The main problems are reflected in two aspects. On the one hand, the composition of rainwater in the initial stage of pavement is very complex and the pollution load is relatively high. If untreated rainwater is directly discharged at the initial stage, it will inevitably pollute the surrounding water bodies. On the other hand, the occurrence of accidents while transporting dangerous goods is also a common cause of pollution in source water protection areas. It is also one of the main causes of environmental damage during the source water protection period. It is necessary to take it as the key thinking direction in the design stage of emergency pool.

\section{Accident risk analysis}

During accidents while transporting dangerous goods, pollutants may have a very key impact on the sources of drinking water. Taking the analysis after a traffic accident of an oil transport vehicle as an example, this case is discussed further. The water intake of a water plant around the water source is about 2 kilometers away from the accident site, while the water plant itself is 7 kilometers away from the site. Based on this parameter, the possible impact of oil spill accident is analyzed and predicted.

If oil and other slightly water-soluble substances enter the river after the accident and float on the water surface in a membrane form, Fay formula can be used to predict the impact. 
Technicians can use the Fay formula to divide the expansion of oil film into three stages. The calculation formula of the inertial expansion stage is as follows:

$$
D_{1}=2 K_{1}\left(g \Delta V^{2}\right)^{1 / 4}
$$

The calculation formula of the viscous expansion stage is as follows:

$$
D_{2}=2 K_{2}\left(\frac{g \Delta V^{2}}{\sqrt{\gamma_{w}}}\right)^{1 / 6} t^{1 / 4}
$$

The calculation formula of the surface tension expansion stage is as follows:

$$
D_{3}=2 K_{3}\left(\frac{\delta}{\rho_{w} \sqrt{\gamma_{w}}}\right)^{1 / 2} t^{3 / 4}
$$

At the end of subsequent diffusion, the area is calculated as follows:

$$
\begin{aligned}
& A_{f}=10^{5} V^{3 / 4} \\
& \Delta=1-\rho_{0} / \rho_{\mathrm{w}}
\end{aligned}
$$

In the above formula, $\mathrm{D}_{1}, \mathrm{D}_{2}$, and $\mathrm{D}_{3}$ represent the oil film diameter $(\mathrm{m})$ of three stages; $\mathrm{A}_{\mathrm{f}}$ represents the area at the end of diffusion $\left(\mathrm{m}^{2}\right)$; g represents the acceleration of gravity $\left(\mathrm{m} / \mathrm{s}^{2}\right)$; V is the total volume of oil, assuming it as $3 \mathrm{~m}^{3}$; t represents the time since the overflow (s); $\delta$ represents the net surface tension coefficient, $\delta=\delta_{\mathrm{aw}}-\delta_{\mathrm{oa}}-\delta_{\mathrm{ow}}$, assuming it as $0.03 \mathrm{~N} / \mathrm{m} ; \delta_{\mathrm{aw}}$ is the surface tension coefficient between air and water $(\mathrm{N} / \mathrm{m}) ; \delta_{\text {oa }}$ is the surface tension coefficient between oil (liquid) and air $(\mathrm{N} / \mathrm{m})$; $\delta_{\text {ow }}$ represents the surface tension coefficient between oil (liquid) and water $(\mathrm{N} / \mathrm{m}) ; \rho_{0}$ is the density of oil (liquid), assuming it as $800 \mathrm{~kg} / \mathrm{m}^{3} ; \rho_{\mathrm{w}}$ represents the density of water, assuming it as $1,000 \mathrm{~kg} / \mathrm{m}^{3} ; \gamma_{\mathrm{w}}$ is the coefficient of kinematic viscosity of water, assuming it as $1.01 \times 10^{-6} \mathrm{~m}^{2} / \mathrm{s} ; \mathrm{K}_{1}, \mathrm{~K}_{2}$, and $\mathrm{K}_{3}$ are empirical coefficients of $1.14,1.45$, and 1.6 , respectively.

Finally, if technicians want to master the boundary time of each stage, they can also use the same conditions of the expansion diameter of adjacent stages.

When calculating the oil film drift distance, it should be noted that the oil will drift and diffuse under the influence of water flow and wind speed soon after entering the water. Therefore, the specific scope of oil spill pollution is the expanding and drifting equivalent circular film ${ }^{[1]}$. In the calculation stage, the initial position of the center of the membrane can be set as $\mathrm{x}_{0}$, and the elapsed time as $\mathrm{t}^{[2]}$, while the position is expressed as $\mathrm{x}$. The specific calculation formula is as follows:

$$
x=x_{0}+\int_{t_{0}}^{t_{0}+\Delta t} v_{0} d t, \overrightarrow{v_{0}}=\overrightarrow{v_{1}}+\overrightarrow{v_{2}}
$$

Wherein, $\overrightarrow{v_{1}}$ is the surface flow drift velocity vector; $\overrightarrow{v_{2}}$ is the surface wind drift velocity vector; $v_{2}$ $=0.035 \mathrm{x} \mathrm{V}^{10} ; \mathrm{x}_{0}$ is the initial position; $\mathrm{t}_{0}$ is the initial time; $\Delta_{\mathrm{t}}$ is the time interval.

The predicted oil film extension results are shown in Table 1. 
Table 1. Predicted oil film extension results

\begin{tabular}{ccccc}
\hline Time $/ \mathrm{s}$ & Diameter $/ \mathrm{m}$ & Area $/ \mathrm{m}^{2}$ & Thickness $/ \mathrm{mm}$ & Drift distance $/ \mathrm{m}$ \\
\hline 30 & 19.4 & 297.0 & 10.10 & 65 \\
60 & 27.5 & 594.0 & 5.05 & 131 \\
120 & 38.9 & 1188.0 & 2.53 & 261 \\
180 & 47.6 & 1782.0 & 1.68 & 392 \\
240 & 55.0 & 2376.0 & 1.26 & 522 \\
283 & 59.7 & 2801.7 & 1.07 & 616 \\
301 & 61.6 & 2978.1 & 1.01 & 655 \\
600 & 73.2 & 4204.6 & 0.71 & 1305 \\
715 & 76.4 & 4589.9 & 0.65 & 1555 \\
900 & 90.8 & 6481.9 & 0.46 & 1958 \\
1000 & 98.3 & 7591.7 & 0.40 & 2175 \\
3000 & 224.1 & 39447.5 & 0.08 & 6525 \\
5000 & 328.7 & 84877.5 & 0.04 & 10875 \\
6000 & 376.9 & 111574.4 & 0.03 & 13050 \\
7000 & 423.1 & 140599.8 & 0.02 & 15225 \\
\hline
\end{tabular}

The corresponding extended eigenvalues are shown in Table 2.

Table 2. Characteristic values of oil film extension

\begin{tabular}{cc}
\hline Project & Petroleum \\
\hline Inertial expansion phase / s & $0-301$ \\
Viscosity expansion stage / s & $301-633$ \\
Surface tension expansion stage /s & $633-8819$ \\
10 min equivalent circle radius / m & 34.5 \\
10 min thickness / mm & 0.67 \\
Critical thickness /mm & 0.01 \\
\hline
\end{tabular}

\section{Determination of tank capacity}

China stipulates that the quality of the tank body of the special tank vehicle needs to pass the inspection of the quality supervision department and can only be put into use after passing the inspection ${ }^{[3]}$. It should be noted that when transporting goods with explosion risk and strong corrosivity, the tank volume of the special tank vehicle should be less than $20 \mathrm{~m}^{3}{ }^{[4]}$, while the transportation of highly toxic goods, the volume of the special tank vehicle should be less than $10 \mathrm{~m}^{3}$. If non-tank vehicles are used to transport highly toxic, explosive, and highly corrosive goods, the load mass of the vehicle should be $\leq 10$ tons ${ }^{[5]}$.

At present, the largest specification of water tank fire trucks in China is $20 \mathrm{~m}^{3}$; the maximum specifications of foam fire engines can hold $12 \mathrm{~m}^{3}$ of water and $3 \mathrm{~m}^{3}$ of foam. Once there is fire on any vehicle on the road, two to three fire engines can complete the fire-fighting task.

The specific tank capacity needs to be determined in terms of the adverse water volume; that is, the amount of leakage from a large hazmat vehicle and the amount of water required by two heavy fire trucks to extinguish the fire simultaneously. Generally speaking, the tank capacity is set to $80 \mathrm{~m}^{3}$, with an adjusted volume of $15 \mathrm{~m}^{3}$. 


\section{Tank body design}

According to the analysis of a large number of experimental data, $50 \%$ to $60 \%$ of the total pollutants in surface runoffs are included in initial runoffs with $2 \mathrm{~mm}$ precipitation. In source water protection areas, the hazardous chemicals from transportation vehicle accidents would inevitably affect the safety of drinking water, and eventually cause irretrievable water pollution events. If there is an emergency pool under the bridge, attention should be paid to its two functions; that is, in the normal operation stage, the pool can collect the rainwater on the bridge deck, isolate, precipitate, and discharge it, so as to reduce the pollution of rainwater to the water source. In case of leakage of dangerous goods, pollutants can also be stored in the emergency pool together with fire-fighting wastewater, so as to effectively avoid accidental pollution to the water source.

The operation process of an emergency pool is shown in Figure 1.

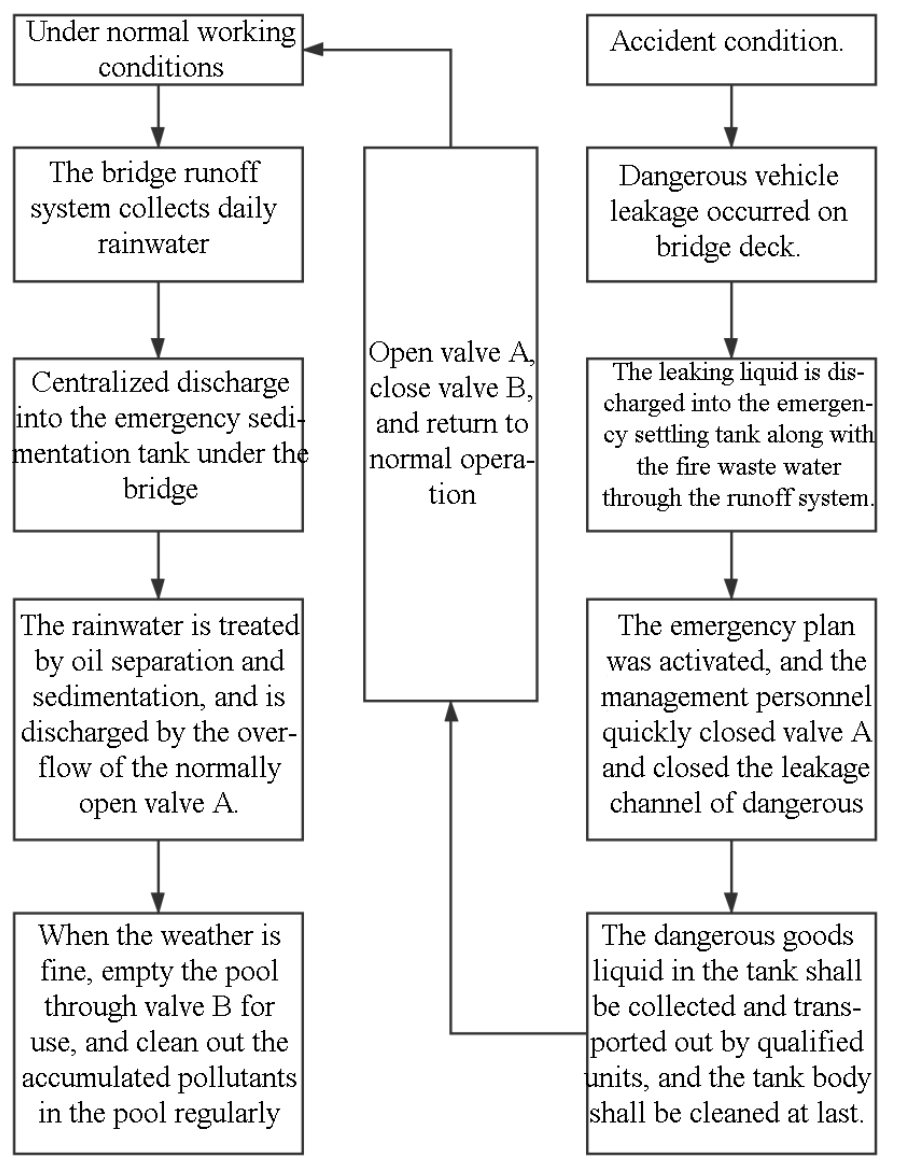

Figure 1. Operation process of emergency pool

\section{Empirical analysis}

\subsection{Project overview}

A bridge crosses the secondary source water protection area. In order to avoid environmental pollution caused by initial rainwater and accident wastewater from the bridge deck entering the water body, technicians need to use reasonable design measures to avoid serious wastewater pollution from accidents.

\subsection{Design criteria}

According to the Environmental Protection Engineering Design Standard for Chemical Engineering 
Construction Projects (GB/T 50483-2019), the effective volume of emergency pool can be calculated as shown below.

The effective volume of emergency pool

= maximum calculated volume of accident wastewater - the effective volume of relevant cofferdam, ring ditch, pipe, and other facilities that can temporarily store accident wastewater

Wherein, the maximum calculated amount of accident wastewater refers to the sum of the following three: (1) the material storage of a maximum capacity of a device or storage tank; (2) the amount of firewater needed in case of fire in the installation area or storage tank area, including the amount of water or foam needed to extinguish the fire and the amount of water needed to protect the adjacent equipment as well as storage tank; (3) rainfall mixed into the wastewater collection system during the accident.

The firewater consumption is represented by $\mathrm{V}_{2}$. According to the technical standard, the firewater consumption is set as $15 \mathrm{~L} / \mathrm{s}$, and the fire time of accident design is set as 2 hours. The final calculation formula is as follows:

$$
\mathrm{V}_{2}=15 \times 2 \times 3.6=108 \mathrm{~m}^{3}
$$

The rainfall of accident design firefighting time is expressed as $V_{3}$, and the time is set to 2 hours. The calculation formula is as follows:

$$
\mathrm{V}_{3}=\mathrm{Qt}=\mathrm{q} \varphi \mathrm{Ft}=77.516 \times 0.9 \times 3300 / 10^{4} \times 2 \times 3600 / 10^{3}=165 \mathrm{~m}^{3}
$$

The project does not consider the clearance capacity in the device or tank farm embankment, so it is assumed as 0 . At the same time, the accident wastewater pipe in the project is not long, so it is assumed as 0 for safety reasons.

Finally, the volume of the sedimentation tank is set as $293 \mathrm{~m}^{3}$, the design value is $300 \mathrm{~m}^{3}$, and the length, width, and height are $10 \mathrm{~m}, 10 \mathrm{~m}$, and $3 \mathrm{~m}$, respectively.

In addition, the effective volume of rainwater storage tank also needs to be calculated for the implementation of diversion system and pollution control of drainage system in the project. The calculation formula is as follows:

$$
\mathrm{V}=10 \mathrm{DF} \varphi \beta
$$

$\mathrm{V}$ refers to the effective volume of the storage tank, and D refers to the storage capacity. Generally, it is $4-8 \mathrm{~mm}$ according to the rainfall; the value in this design is $6 \mathrm{~mm}$. The final calculation results are as follows:

$$
\mathrm{V}=10 \times 6 \times 0.33 \times 0.9 \times 1.3=23.166 \mathrm{~m}^{3}
$$

For the sake of calculation, it is assumed as $24 \mathrm{~m}^{3}$.

\subsection{Tank body design}

The volume of the emergency pool needs to be larger than that of the initial rainwater storage pool. As a key measure to protect the water source, engineering technicians have chosen to station emergency pools on both sides of the roundabout bridge in the surrounding interchange to collect the wastewater generated 
by the two ramps and the initial rainwater.

In general, the emergency pool only needs to collect the rainwater on the bridge deck to promote it to be discharged into the natural water body after being precipitated by isolation oil. The advantage of this is that it can reduce the pollution of the initial rainwater to the water source, and the initial rainwater itself can also be discharged to the nearest sewage treatment plant through the municipal sewage pipeline. Even if there is a leakage accident on the bridge deck, the pollutants can be stored in the emergency pool along with the firefighting wastewater to be centrally treated later.

The daily operation process of the project is divided into two situations. One is under normal working conditions: normally open valve A, normally closed valve B, and the bridge deck collects daily rainwater by runoff. After sedimentation treatment, it would overflow and be discharged into the rainwater pipeline. When the rain stops, valve B can be opened, the initial rainwater would be discharged into the municipal sewage pipe, and the valve would be closed after the sedimentation tank.

Another situation is that in case of an accident on the bridge deck, the emergency center would close both valves, completely cut off the connection between the pollutants and the water system, as well as use a suction to send pollutants in the sedimentation tank to relevant treatment institutions for treatment. It should be noted that the accident treatment time should be less than 2 hours.

\section{Conclusion}

In conclusion, in the design of emergency pools in source water protection areas, attention should be paid to the impact of initial rainwater pollution and dangerous goods transportation on the water body. The most feasible treatment method should be to set up emergency pools, and at the same time, in the design stage, comprehensive consideration should be given to the sedimentation tank capacity as well as the optimization measures of the tank body and other design details.

\section{Disclosure statement}

The author declares that there is no conflict of interest.

\section{References}

[1] Xu L, 2021, Example of Sewage Treatment Plant Design in an Industrial Park in Xinjiang. Construction \& Design for Project, 2021(09): 90-92.

[2] Sun X, 2019, Design of Runoff Collection and Emergency Response System for Bridge Deck. Urban Roads Bridges and Flood Control, 2019(07): 161-163, 21.

[3] Li Z, 2019, Discussion on Design of Accident Sedimentation Tank in Water Source Protection Area. Urban Roads Bridges and Flood Control, 2019(06): 178-179, 20-21.

[4] Wang D, 2017, Design of Tianjin Port Sewage Treatment Plant Upgrade and Reconstruction Project. Petrochemical Industry Technology, 24(11): 19-21.

[5] Wang Q, He X, Su H, et al., 2016, Discussion on Design of Emergency Sedimentation Tank for Highway Bridge Head in Water Source Protection Area. China Water \& Wastewater, 32(16): 73-76.

Publisher's note

Bio-Byword Scientific Publishing remains neutral with regard to jurisdictional claims in published maps and institutional affiliations. 